\title{
MicroRNA-137 exerts protective effects on hypoxia-induced cell injury by inhibiting autophagy/mitophagy and maintaining mitochondrial function in breast cancer stem-like cells
}

\author{
QIONGYING HU ${ }^{1 *}$, YUN YUAN $^{2 *}$, YEKE WU $^{3}$, YONGLIANG HUANG $^{4}$, ZIYI ZHAO $^{5}$ and CHONG XIAO $^{6}$ \\ ${ }^{1}$ Department of Laboratory Medicine, Hospital of Chengdu University of Traditional Chinese Medicine; \\ ${ }^{2}$ College of Medical Technology, Chengdu University of Traditional Chinese Medicine; Departments of ${ }^{3}$ Stomatology, \\ ${ }^{4}$ Pharmacy and ${ }^{5}$ Central Laboratory, Hospital of Chengdu University of Traditional Chinese Medicine; \\ ${ }^{6}$ Teaching and Research Office of Oncology, Hospital of Chengdu University of Traditional Chinese Medicine, \\ Chengdu, Sichuan 610072, P.R. China
}

Received March 20, 2020; Accepted July 10, 2020

DOI: $10.3892 /$ or.2020.7714

\begin{abstract}
Breast cancer stem-like cells (BCSCs) have been identified and proven to play critical roles in tumorigenesis and progression. Hypoxia is a common pathologic feature of breast cancer and potentially, at least in part, regulates the initiation, progression, and recurrence of breast cancer. However, less is known about how hypoxia regulates BCSCs. As several well-known microRNAs respond to hypoxia, we aimed to determine how hypoxia regulates the physiological processes of BCSCs by regulating the corresponding microRNAs. As expected, microRNA-137 (miRNA-137 or miR-137) was downregulated upon hypoxic exposure, indicating that it may play critical roles in BCSCs. Introduction of miR-137 mimics promoted cell cycle entry and inhibited hypoxia-induced cell apoptosis as determined by cell cycle assay and apoptosis assay. By detecting mitochondrial reactive oxygen species (ROS), it was found that miR-137 inhibited ROS accumulation induced by hypoxic exposure and thus suppressed cell apoptosis. Introduction of miR-137 mimics under hypoxia inhibited mitophagy/autophagy by targeting FUN14 domain containing 1 (Fundc1) and thus promoted mitochondrial functions, including mitochondrial mass, ATP synthesis and
\end{abstract}

Correspondence to: Dr Ziyi Zhao, Central Laboratory, Hospital of Chengdu University of Traditional Chinese Medicine, 39 Shierqiao Road, Jinniu, Chengdu, Sichuan 610072, P.R. China

E-mail: zhaoziyi925@163.com

Dr Chong Xiao, Teaching and Research Office of Oncology, Hospital of Chengdu University of Traditional Chinese Medicine, 39 Shierqiao Road, Jinniu, Chengdu, Sichuan 610072, P.R. China

E-mail: xiaochong@stu.cdutcm.edu.cn

*Contributed equally

Key words: miR-137, breast cancer stem-like cells, hypoxia, mitochondrial dysfunction, reactive oxygen species mitochondrial transcriptional activity, which was similar to the effects of Fundc1 knockdown by specific siRNA. Based on these observations, we hypothesized that the survival of BCSCs under hypoxia was mediated by miR-137 by regulating mitochondrial dysfunction. We demonstrated here that the introduction of exogenous miR-137 promoted mitochondrial function, indicating that it may be a potential therapeutic target in BCSCs.

\section{Introduction}

Worldwide, breast cancer, which is induced by diverse factors, such as heredity and lifestyle, is the most frequently diagnosed cancer and the leading cause of cancer-related deaths among women $(1,2)$. Breast cancer stem-like cells (BCSCs) are heterogeneous tumor cells with self-renewal ability and multidifferentiation potential that participate in tumorigenesis, metastasis and therapy resistance of breast cancer (3). Many studies have demonstrated that BCSCs play an essential role in the poor clinical outcome of breast cancer by investigating markers, ALDH(+), CD44(+) and CD24(-) (4-7). In addition, the BCSC-related signaling pathways, Wnt, Notch and hedgehog, are involved in malignant tumor behavior, such as proliferation, colony formation and migration (8-10). Therefore, drugs targeting these signaling pathways are promising treatment strategies (11-13).

Hypoxia is a common tumor microenvironment phenomenon that is characterized by decreased oxygen levels in tissues. Hypoxia affects the survival of cells, including disseminated tumor cells (DTCs), through transcriptional, metabolic and mobility changes $(14,15)$. Mitochondria are the major consumer organelles, as well as the potential source of reactive oxygen species (ROS). The lack of oxygen results in mitochondrial fusion and fission, mitophagy, oxidative phosphorylation and eventually mitochondrial dysfunction (16). Hypoxia has been confirmed to exert a crucial effect on the viability of CSCs (17). It has become increasingly clear that hypoxia impacts cellular processes through a group of genetic transcription activators termed hypoxia-inducible factors 
(HIFs) (18). HIFs are composed of an alpha (HIF- $\alpha$ ) and a beta (HIF- $\beta$ ) subunit, and the oxygen-dependent HIF- $\alpha$ subunit is the key protein determining the transcriptional activity of HIFs, while the HIF- $\beta$ subunit is structurally expressed in the cell nucleus (19). A large number of reports have revealed that oxygen deficit induces the generation of HIFs in human embryonic stem cells (hESCs), which have the ability to activate the Wnt and Notch self-renewal signaling pathways $(20,21)$ and vascular endothelial growth factors (VEGFs) so that HIFs can maintain cells in an undifferentiated state and promote tumor vessel formation (22).

MicroRNAs (miRNAs or miRs) are small noncoding single-stranded RNAs with a length of 22 nucleotides that affect the regulation of posttranscriptional gene expression (23). During a hypoxic period, specific miRNAs, called hypoxia-regulated miRNAs (HRMs), are differentially expressed, some of which are downregulated while others are upregulated (24). MicroRNA-137 (miRNA-137 or miR-137) is considered a representative HRM (25). Li et al (26) concluded that miR-137 effectively protected retinal ganglion cells against hypoxia-induced apoptosis by attenuating Notch1 expression. One study demonstrated that miR-137 could promote $\mathrm{PI} 3 \mathrm{~K} / \mathrm{AKT} / \mathrm{mTOR}$ and ERK pathway activation to induce mitophagy and autophagy of brain cells exposed to hypoxia (27). Moreover, microRNA-210 (miRNA-210 or miR-210) is regarded as the main hypoxia-controlled RNA (24), and Wang et al discovered that miR-210 exerted a negative effect on HIF1- $\alpha$ protein expression, accompanied by the activation of $\mathrm{T}$ cells (28). Interestingly, results from various experiments have shown that miRNAs share a strong connection with mitochondria. Primarily, miRNAs affect mitochondrial metabolism and dynamics by positively regulating translation (29-32). Moreover, the levels of some miRNAs are abnormal in different types of cancer (33). For example, miR-34 accelerates gastric cancer progression by maintaining cancer stemness properties (34).

The studies mentioned above provide insight into the role of hypoxia in malignant tumor behaviors, including the expression of miRNAs and the function of mitochondria (35-37). However, the mechanism by which hypoxia regulates mitochondrial function and mitophagy by affecting miRNA expression remains largely unclear. In the present study, we examined the mitochondrial function in BCSCs after deoxygenation and analyzed the related microRNAs to characterize the underlying regulatory mechanism.

\section{Materials and methods}

Cell culture. The human breast cancer cell lines SKBR-3, MCF-7, MDA-MB-231 were acquired from the American Type Culture Collection (ATCC). Cells were maintained in high-glucose Dulbecco's modified Eagle's medium (DMEM; Gibco; Thermo Fisher Scientific, Inc.) containing 10\% fetal bovine serum (FBS, Gibco; Thermo Fisher Scientific, Inc.) and incubated at $37^{\circ} \mathrm{C}$ with $95 \%$ humidity and $5 \% \mathrm{CO}_{2}$.

Macrospheroidformation.SKBR-3, MCF-7 and MDA-MB-231 cells were cultured in serum-free medium (SFM) consisting of DMEM/F-12 (Gibco; Thermo Fisher Scientific, Inc.) (1:1), 2\% B27 (Invitrogen; Thermo Fisher Scientific, Inc.), 10 ng/ml
EGF and $10 \mathrm{ng} / \mathrm{ml} \mathrm{bFGF}$ (PeproTech, Inc.). The medium was half-refreshed every three days. Three weeks later, spheroids were obtained. The collected spheroids were stained with an ALDEFLUOR ${ }^{\mathrm{TM}}$ assay kit (Stem Cell Technologies). The proportions of newly formed tumor stem cell spheres were isolated by ALDH-positive cell sorting.

Treatments. $\mathrm{CoCl}_{2}$ (Sigma-Aldrich; Merck KGaA) was dissolved in DMEM at a concentration of $100 \mathrm{mM}$. To mimic hypoxic conditions, $100 \mathrm{mM} \mathrm{CoCl}_{2}$ was added to the three breast cancer cell lines for 24,48 , and $72 \mathrm{~h}$, and BCSCs were transfected with miR-137 mimics for 12 and $24 \mathrm{~h}$ for further examination. LW-6 (cat. no. S8441; Selleck Chemicals) was dissolved in dimethyl sulfoxide (DMSO) at a concentration of $25 \mathrm{mM}$. BCSCs were treated with DMEM containing $10 \mathrm{ng} / \mathrm{ml}$ LW-6 or DMSO (control group) for 12 or $24 \mathrm{~h}$ to explore the role of miR-137 mimics.

Cell transfection. BCSCs were cultured in 6-well plates with DMEM containing 10\% FBS. For each well, $5 \mu \mathrm{l}$ Lipofectamine ${ }^{\circledR} 2000$ reagent (Invitrogen; Thermo Fisher Scientific, Inc.) was diluted in $250 \mu \mathrm{l}$ Opti-MEM I reduced serum medium (Gibco; Thermo Fisher Scientific, Inc.). A total of $62.5 \mathrm{pmol}$ of miR-137 mimics or miR-137 negative control mimics, miR-210 inhibitor or miR-210 negative control inhibitor (RiboBio) was diluted in $250 \mu \mathrm{l}$ Opti-MEM and incubated at room temperature for $5 \mathrm{~min}$. A total of $250 \mu \mathrm{l}$ diluted miRNAs and $250 \mu \mathrm{l}$ diluted reagent Lipofectamine ${ }^{\circledR} 2000$ were mixed and used according to the manufacturer's instructions. The transfected cells were incubated at $37^{\circ} \mathrm{C}$ with $95 \%$ humidity and $5 \% \mathrm{CO}_{2}$. After $12 \mathrm{~h}$, when transfection efficiency $>80 \%$ was observed by fluorescence microscopy, relevant experiments were subsequently performed.

Aldefluor assay. The cells were washed with phosphate-buffered saline (PBS) twice and centrifuged at $150 \mathrm{x} \mathrm{g}$ for $5 \mathrm{~min}$. The cell concentration was adjusted to approximately $2 \times 10^{5}$ cells $/ \mathrm{ml}$ suspended in assay buffer. A $1 \mathrm{ml}$ sample suspension was placed into each test tube. Next, $5 \mu \mathrm{l}$ of ALDEFLUOR $^{\text {TM }}$ DEAB reagent was placed into the control tube, and $5 \mu \mathrm{l}$ of activated ALDEFLUOR ${ }^{\mathrm{TM}}$ reagent (StemCell Technologies) was added into the test tube. Then, $0.5 \mathrm{ml}$ of the mixed solution was transferred from the test tube to the control tube. After incubation for $30 \mathrm{~min}$ at $37^{\circ} \mathrm{C}$, all tubes were centrifuged at $250 \mathrm{x}$ g for $5 \mathrm{~min}$, and the supernatant was removed. Finally, the Alde Fluor assay was performed by a 3-laser Navios flow cytometer (Beckman Coulter). The data files were analyzed using FlowJo 9.7.6 (FlowJo LLC).

Western blot analysis. The cell lysates were extracted using radio immunoprecipitation assay (RIPA) lysis buffer and the protein concentrations were measured using BCA Protein assay kit (Sigma-Aldrich; Merck KGaA). An amount of $20 \mu \mathrm{g}$ of total proteins was separated on $10-15 \%$ sodium dodecyl sulfate-polyacrylamide gel electrophoresis (SDS-PAGE) and transferred onto polyvinylidene fluoride membranes (PVDF; Thermo Fisher Scientific, Inc.). After blocking with 5\% milk in $0.1 \%$ Tween-20 PBS (PBS-T) at room temperature for $1 \mathrm{~h}$, the membranes were incubated with primary antibodies for Oct-4 (dilution 1:1,000, cat. no. ab222233), Nanog (dilution 1:2,000, 
cat. no. ab218524), Fundc1 (dilution 1:1,000, cat. no. ab224722), NIX (dilution 1:1,000, cat. no. ab8399), LC3B (dilution 1:500, cat. no. ab48394), Tomm20 (dilution 1:2,000, cat. no. ab56783), VADC (dilution 1:2,000, cat. no. ab81673), Tim23 (dilution $1: 2,000$, cat. no. ab230253) and $\beta$-actin (dilution 1:5,000, cat. no. ab8226) at $4^{\circ} \mathrm{C}$ overnight. Then, the membranes were washed three times with PBS-T and incubated with secondary antibodies (goat anti-rabbit IgG antibody, dilution 1:5,000, cat. no. 6721) at room temperature for $1 \mathrm{~h}$. All antibodies were purchased from Abcam. After washing with PBS-T three times, blots were imaged and analyzed on an X-ray film and quantified using Image J software (version 1.46; National Institutes of Health, Bethesda, MD, USA).

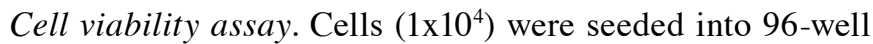
plates and allowed to attach overnight. To detect cell viability, the medium was replaced with fresh medium, and $10 \mu \mathrm{l}$ of Cell Counting Kit-8 (CCK-8) (Sigma-Aldrich; Merck KGaA) solution was added to each well for $1 \mathrm{~h}$ at $37^{\circ} \mathrm{C}$. The optical density (OD) was analyzed using a multifunctional microplate reader (FlexStation 3; Molecular Devices) within $2 \mathrm{~h}$.

Reverse transcription and quantitative PCR (RT-qPCR). Cells were lysed using SoniConvert ${ }^{\circledR}$ sonicator (DocSense) following the manufacturer's instructions and then total RNA was isolated using the miRcute miRNA Isolation kit [Tiangen Biotech (Beijing) Co., Ltd.]. Reverse transcription was performed using SYBR ${ }^{\circledR}$ Green PCR Master Mix (Thermo Fisher Scientific, Inc.) following the manufacturer's instructions. The primer sequences were as follows: miR-137 (forward 5'-GCGCGCTTATTGCTTAAGAATAC-3' and reverse 5'-GTCGTATCCAGTGCAGGGTCCGAGGTATTC GCACTGGATACGACCTACGC-3'); miR-210 (forward 5'-CCAGTGCAGGGTCCGAGGTATTC-3' and reverse 5'-TGTCGGTGTGACAGGCGC-3'); miR-9 (forward 5'-CGT TCGTCTCTTTGGTTATCTAGC-3' and reverse 5'-AAT GGTTGATCTGCTCTCTCTCTC-3'); mtF805 (5'-CCACGG GAAACAGCAGTGATT-3'); mtR927 (5'-CTATTGACT TGGGTTAATCGTGTGA-3'); COXI (upstream 5'-AGCAGG AATAGTAGGGA-3' and downstream 5'-GGAATCAGT GGACGAA-3'); ND1 (upstream 5'-ATACGCCCTCTAACC ACC-3' and downstream 5'-GAATTTGAGGCTCATCCC-3'); $\beta$-actin (forward 5'-CATGTACGTTGCTATCCAGGC-3' and reverse 5'-CTCCTTAATGTCACGCACGAT-3'). All primers were purchased from Sangon Biotech. Quantitative real-time polymerase chain reaction (qPCR) of miR-137 in cells was conducted using the Applied Biosystems 7500 Fast Real-Time PCR system (Applied Biosystems). The amplification conditions were as follow: 40 cycles of denaturation at $95^{\circ} \mathrm{C}$ for $15 \mathrm{sec}$, annealing and extension at $60^{\circ} \mathrm{C}$ for $1 \mathrm{~min}$. The calculations of expression of target genes were relative quantification, and $2^{-\Delta \Delta \mathrm{Cq}}$ represented relative gene expression (38). Each sample was tested three times. $\beta$-actin was used as an internal control for normalization.

Cell cycle assay. A total of $2 \times 10^{6}$ cells were fixed with $75 \%$ ice-cold ethanol for $12 \mathrm{~h}$ at $4^{\circ} \mathrm{C}$. Fixed cells were pelleted by centrifugation and washed with ice-cold PBS. Then, $400 \mu 1 \mathrm{PBS}$ containing $50 \mu \mathrm{g} / \mathrm{ml}$ propidium iodide (PI) (Sigma-Aldrich; Merck KGaA), $100 \mu \mathrm{g} / \mathrm{ml}$ RNase A and 0.2\% Triton X-100 was added to the cells and coincubated for $30 \mathrm{~min}$ in the dark. Cells were analyzed for cell cycle phase distribution by a 3-laser Navios flow cytometer (Beckman Coulter). The data were analyzed using FlowJo 9.7.6 (FlowJo LLC).

Apoptosis assay. A total of $1 \times 10^{6}$ cells were suspended in $100 \mu \mathrm{l} 1 \mathrm{X}$ binding buffer, $5 \mu \mathrm{l}$ Annexin V fluorescein isothiocyanate and $5 \mu \mathrm{l}$ propidium iodide (PI; BD Biosciences) in the dark for $20 \mathrm{~min}$ at room temperature. Then, $400 \mu \mathrm{l}$ of $1 \mathrm{X}$ binding buffer was added, and stained cells were analyzed by using a 3-laser Navios flow cytometer (Beckman Coulter). The data were analyzed using FlowJo 9.7.6.

Measurement of mitochondrial ROS in BCSCs. Cells were washed with PBS three times and incubated with working solution containing $5 \mu \mathrm{M}$ MitoSOX ${ }^{\mathrm{TM}}$ reagent (Thermo Fisher Scientific, Inc.) for $10 \mathrm{~min}$ at $37^{\circ} \mathrm{C}$ in the dark. Then, the cells were washed with PBS and imaged using an X71 (U-RFL-T) fluorescence microscope at x400 magnification (Olympus).

Measurement of intracellular ROS in BCSCs. After being washed with ice-cold PBS three times, the cells were resuspended in pre-warmed PBS containing $5 \mu \mathrm{M}$ intracellular ROS-specific fluorescent probe staining reagent $\mathrm{H}_{2}$ DCFDA (Thermo Fisher Scientific, Inc.) and then incubated in the dark for $30 \mathrm{~min}$ at $37^{\circ} \mathrm{C}$. After being washed three times with pre-warmed PBS, the cells were imaged using an X71 (U-RFL-T) fluorescence microscope at X400 magnification.

Citrate synthase activity assay. A total of $5 \times 10^{4}$ cells were collected and rinsed with ice-cold PBS twice. The cell pellet was solubilized at a concentration of $2 \times 10^{7} / \mathrm{ml}$ in extraction buffer and then incubated on ice for $20 \mathrm{~min}$. After $1,600 \mathrm{x} \mathrm{g}$ centrifugation for $20 \mathrm{~min}$, the supernatants were transferred into a new tube. Thereafter, $100 \mu \mathrm{l}$ of sample was added to each well and incubated hermetically for $3 \mathrm{~h}$ to capture the enzyme. The suspension was extracted and washed twice using $300 \mu \mathrm{l}$ $1 \mathrm{X}$ washing buffer. Then, $100 \mu \mathrm{l} 1 \mathrm{X}$ Citrate Synthase Activity Solution (cat. no. ab119692, Abcam) was added. Finally, the absorbance was analyzed for 5-30 min at 20-sec intervals by a microplate reader (Synergy 2 Multi-Mode Microplate Reader, BioTek) at a wavelength of $412 \mathrm{~nm}$.

ATP synthesis assay. A total of $1 \times 10^{4}$ cells were collected and incubated with $200 \mu \mathrm{l}$ of cell lysis buffer according to the instructions of the ATP Detection kit (Beyotime Institute of Biotechnology). The cells were pipetted up and down several times and centrifuged at 1,200 x $\mathrm{g}$ for $5 \mathrm{~min}$. Then, $100 \mu \mathrm{l}$ supernatant was moved into the prepared well for $5 \mathrm{~min}$ at room temperature. Then, the luminescence of ATP was measured by a microplate reader (Synergy 2 Multi-Mode Microplate Reader, BioTek).

Evaluation of GFP-LC3 fluorescence. A total of $1 \times 10^{5}$ cells were transfected with the GFP-LC3 plasmid (Addgene) for $24 \mathrm{~h}$ and then re-transfected with miR-137 mimics or NC mimics for another $24 \mathrm{~h}$. Then, the cells were washed with PBS three times and incubated with $5 \mu \mathrm{M}$ MitoTracker Red (Thermo Fisher Scientific, Inc.) for $30 \mathrm{~min}$ at $37^{\circ} \mathrm{C}$ in the dark. Cells were fixed with $4 \%$ paraformaldehyde for $10 \mathrm{~min}$ at room 
temperature and re-stained with 4'6-diamidino-2-phenylindole (DAPI, diluted 1:5,000; Thermo Fisher Scientific, Inc.). The colocalization of GFP-LC3 (green dots) and mitochondria (red dots) was imaged using an X71 (U-RFL-T) fluorescence microscope at $\mathrm{x} 400$ magnification.

Statistical analysis. All data were analyzed using SPSS 20.0 software (IBM Corp.). Data are presented as the means \pm SD. The experimental group and control group were compared using Student's t-test. ANOVA followed by Tukey's analysis was used to determine significance for multiple group comparisons. $\mathrm{P}<0.05$ was assigned to indicate a significant difference.

\section{Results}

Enrichment and characterization of BCSCs. To enrich the BCSCs, we cultured human breast cancer cells, SKBR-3, MCF-7, and MDA-MB-231, in serum-free medium with the necessary supplementary cytokines as described previously, and macrospheroids were observed in all of these cell cultures (Fig. 1A, left panel), all of which presented enriched ALDH-positive subpopulations (Fig. 1A, right panel). By performing western blotting, the widely reported stem cell markers Nanog and Oct-4, which have been positively linked with the epithelial-mesenchymal transition (EMT) of cancer stem cells and poor outcomes (39-42), presented significantly higher expression levels in macrospheroids compared to their levels in parental cells (Fig. 1B, $\mathrm{P}<0.05$ ). Then, hypoxic conditions were mimicked by culturing cells in medium supplemented with $100 \mathrm{mM} \mathrm{CoCl}$, and cell viability was evaluated at the $0,24,48$ and $72 \mathrm{~h}$ time points. As shown in Fig. 1C, hypoxic conditions significantly decreased the viability of all BCSCs, as expected. To detect the expression of miR-137 and miR-210, which have been reported as two hypoxia-responsive microRNAs, the expression in these cells was detected at 12 and $24 \mathrm{~h}$ after hypoxia exposure. As expected, without interfering with miR-9, miR-210 was upregulated, while miR-137 was downregulated, in all assessed cell lines (Fig. 1D, $\mathrm{P}<0.05)$.

Effects of miR-137 and miR-210 on cell cycle distribution, cell viability, cell stemness and apoptosis in normoxic and hypoxic conditions. The abovementioned macrospheroids presented similar gene expression profiles, which prompted us to conduct an analysis of hypoxia-responsive microRNAs focusing on MCF-7 BCSCs. To determine the effects of miR-137 and miR-210 on the distribution of cells in cell cycle phases, mimics targeted to miR-137 (miR-137 mimics) or negative control mimics (NC mimics) were transfected into cells, and miR-210 inhibitor or negative control inhibitor (NC inhibitor) was also used for transfection. To confirm the introduction efficacy, after $24 \mathrm{~h}$, qPCR was performed and the results indicated the significant overexpression of miR-137 and miR-210 inhibitor (Fig. S1). The results of PI staining followed by flow cytometry showed that miR-137 overexpression and miR-210 inhibition promoted cell cycle entry by decreasing BCSCs in the G1/G0 phase accompanied with significant increase in $\mathrm{G} 2 / \mathrm{M}$ phase simultaneously (Fig. 2A, $\mathrm{P}<0.05)$. Moreover, the decrease in cell viability shown in Fig. 2B $(\mathrm{P}<0.05)$ demonstrated that high levels of miR-137 or low levels of miR-210 exerted inhibitory effects on BCSCs in normoxic and hypoxic conditions respectively. ALDH-positive cells, known to be closely associated with the stemness of BCSCs (43-45), were found to be decreased upon overexpression of miR-137 or inhibition of miR-210 (Fig. $2 \mathrm{C}, \mathrm{P}<0.05$ ) both in normoxia and hypoxia. As expected, the apoptotic rate was negatively associated with overexpression of miR-137 and inhibition of miR-210 (Fig. 2D, P<0.05). Overall, miR-137 and miR-210 exerted protective effects on MCF-7 BCSCs.

miR-137 significantly inhibits the increase in ROS caused by hypoxia to suppress apoptotic cell death. By performing fluorescent staining experiments, we found that hypoxia induced ROS accumulation in cells and mitochondria compared with the two antioxidant enzyme groups (Fig. 3A). Interestingly, overexpression of miR-137 resulted in less production of ROS under hypoxic conditions (Fig. 3B). To further explore the influence of miR-137 on hypoxia-induced apoptotic cell death, apoptotic cell death was evaluated by Annexin V/PI double staining followed by flow cytometric analysis. These data indicated that in BCSCs, miR-137 had a protective effect on apoptotic cell death (Fig. 3C, $\mathrm{P}<0.05$ ).

miR-137 restores cell mitochondrial dysfunction by inhibiting mitophagy. As numerous articles have reported previously, hypoxia clearly stimulates mitophagy and leads to mitochondrial inactivation $(46,47)$, which prompted us to investigate the role of miR-137 induced by hypoxia in the regulation of MCF-7 BCSC mitochondrial dysfunction. Fundc1, NIX and LC3, representative mitophagy receptor proteins and autophagy-related proteins $(25,48,49)$, were markedly decreased (Fig. 4A). In contrast, Tom20 and VADC, mitochondrial-specific proteins $(50,51)$, were obviously increased. Accordingly, an increase in mitochondrial DNA levels was detected in hypoxic BCSCs after miR-137 transfection by qPCR, which illustrated that miR-137 had a positive correlation with mitochondrial functions (Fig. 4B, $\mathrm{P}<0.05$ ). As shown in Fig. 4C and D $(\mathrm{P}<0.05)$, citrate synthase activity and the levels of synthesized ATP were notably upregulated by the overexpression of miR-137 relative to those in the NC group. Finally, we performed mtDNA transcript analysis in normoxic, mock-, negative control- and miR-137 mimic-transfected cell extracts using COXI and ND1 (Fig. 4E). It was concluded that hypoxia-mediated inhibition of mitophagy and mitochondrial dysfunction were significantly reversed by overexpression of miR-137 $(\mathrm{P}<0.05)$.

miR-137 inhibits mitophagy by posttranscriptionally regulating Fundcl. Considering previously reported findings $(25,52)$, Fundc1, a substrate of mitochondrially localized E3 ubiquitin ligase, participates in hypoxia-induced mitophagy and its 3'UTR has been proven to contain sites complimentary to miR-137. To further confirm the posttranscriptional regulation of Fundc1 protein levels by miR-137, we analyzed Fundc1 protein expression after transfection of miR-137 mimics, and it was observed that the Fundc1 protein level was significantly decreased after miR-137 mimic transfection (Fig. 5A, P<0.05). A decrease in Fundc1 protein was observed to be inversely associated with Tom 20 and Tim23, indicating that miR-137 potentially affected mitochondrial mass by regulating Fundc1 
A
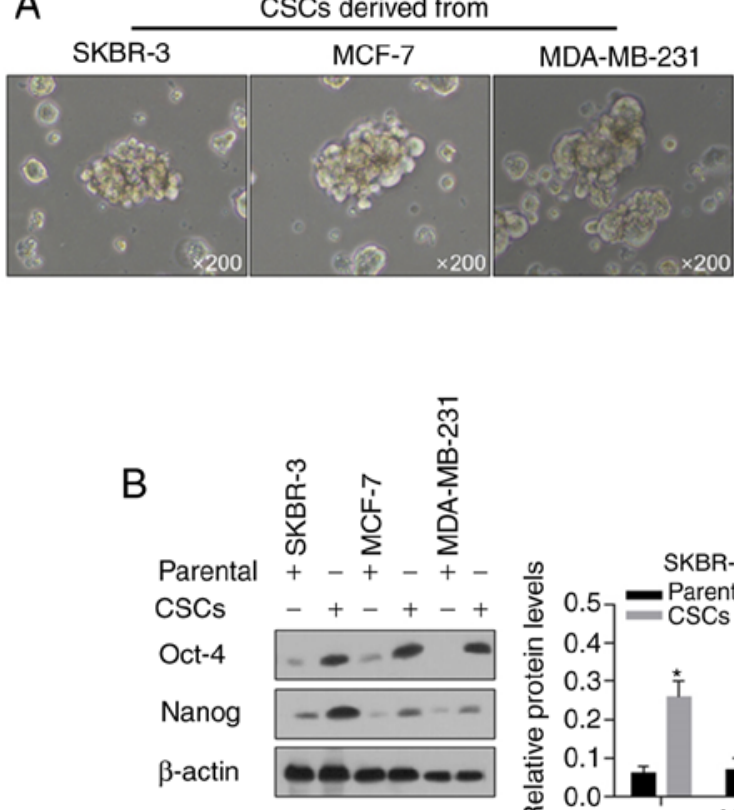

C

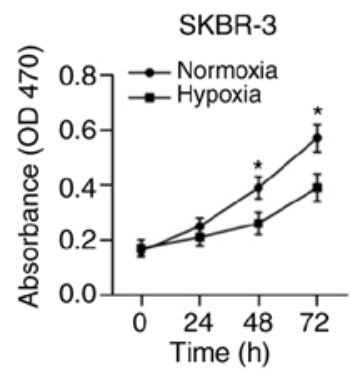

D

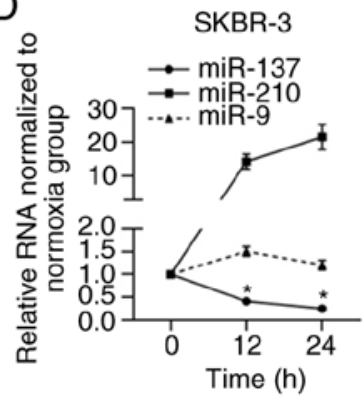

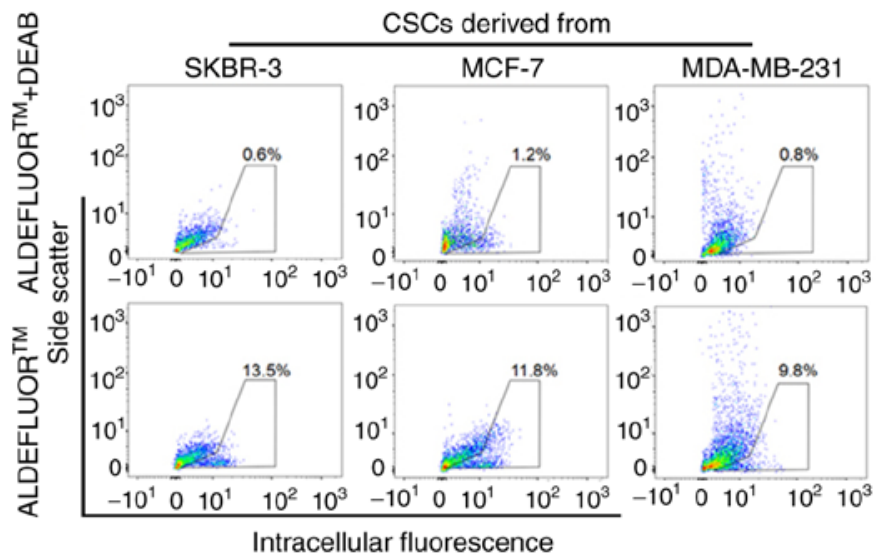

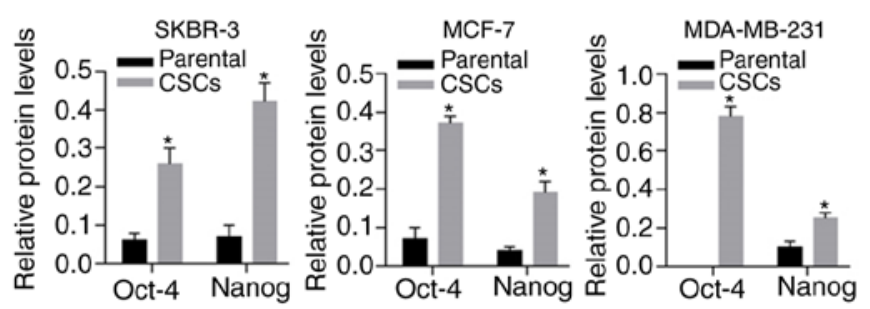

MCF-7

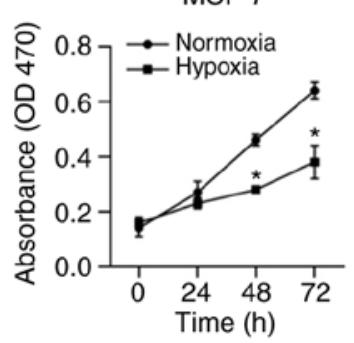

MCF-7

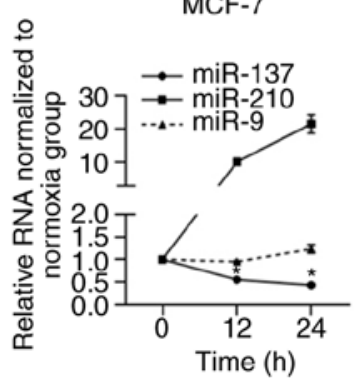

MDA-MB-231

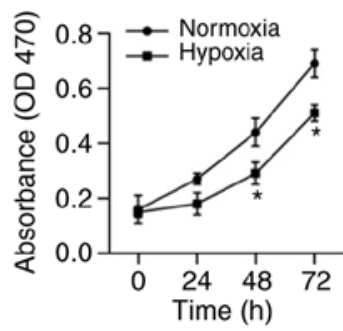

MDA-MB-231

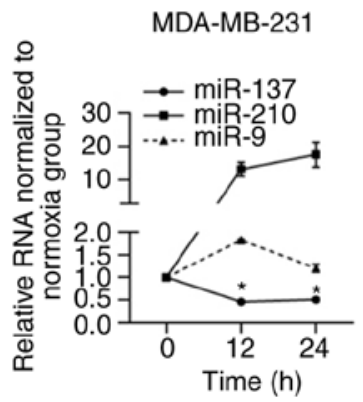

Figure 1. Characteristics of BCSCs and changes in hypoxia. (A) Microscopy images of BCSCs derived from SKBR-3, MCF-7, MDA-MB-231 cells after incubation in serum-free medium (SFM) (left panel) and flow cytometric analysis of ALDH-positive subpopulation of the BCSCs. Numbers in the cytometry charts indicate the percentages of corresponding subpopulations. (right panel). (B) Western blot analysis of Nanog and Oct-4 protein from parental cells and BCSCs (left panel). Nanog and Oct-4 protein expression by statistical analysis (right panels). ${ }^{*} \mathrm{P}<0.05$ vs. Parental group. (C) Cell viability of BCSCs with normoxia treatment or with hypoxia treatment at $0,24,48$ and $72 \mathrm{~h}$ by CCK- 8 assay. "P $<0.05$ vs. Normoxia group. (D) Levels of miR-137, miR-210 and miR-9 in the three types of BCSCs with hypoxia-treatment at 12 and $24 \mathrm{~h}$ were measured by RT-qPCR. " $\mathrm{P}<0.05 \mathrm{vs} .0 \mathrm{~h}$ miR-137 group. BCSCs, breast cancer stem-like cells; ALDH, aldehyde dehydrogenase.

(Fig. 5A). Notably, treatment with LW-6, an inhibitor of the transcriptional activity of HIF-1, exerted similar effects as the introduced miR-137 mimics, indicating that the decrease in miR-137 was potentially caused by transcriptional activity of HIF-1 under hypoxia (Fig. 5A). In experiments on LC3, decreased LC3-II was detected after both miR-137 mimic transfection and LW-6 treatment, confirming that miR-137 mimics inhibited mitophagy (Fig. 5B, P<0.05). Furthermore, mitochondrial staining with MitoTracker Red, GFP-LC3 and DAPI revealed that both miR-137 transfection and LW-6 treatment decreased the colocalization of GFP-LC3 (green dots) with mitochondria (red dots, Fig. 5C, $\mathrm{P}<0.05$ ). Overall, the HIF-1-mediated decrease in miR-137 induced by hypoxia may inhibit mitophagy by targeting Fundc1.

\section{Discussion}

In the present study, by performing analysis of stem cell-like side populations, western blotting, CCK-8 and RT-PCR, it was demonstrated that the macrospheroids of breast cancer 

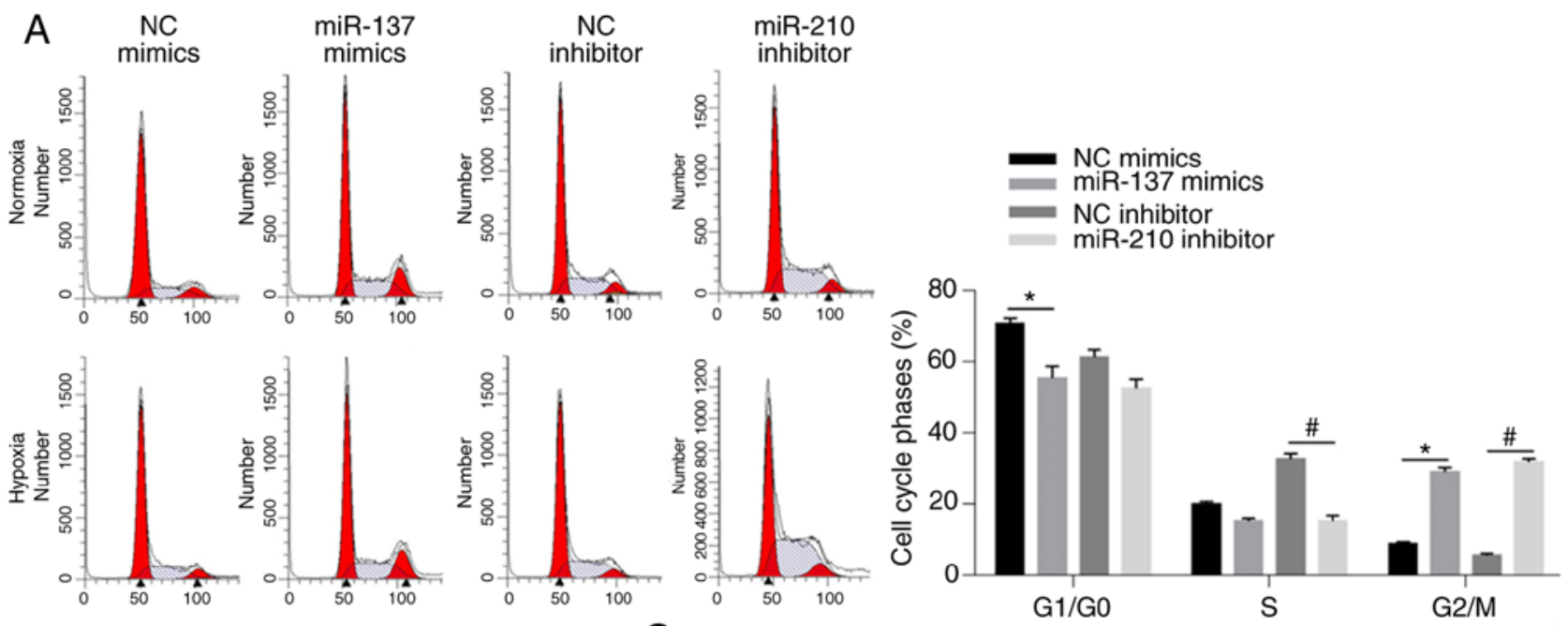

$\mathrm{B}$

C

G1/G0
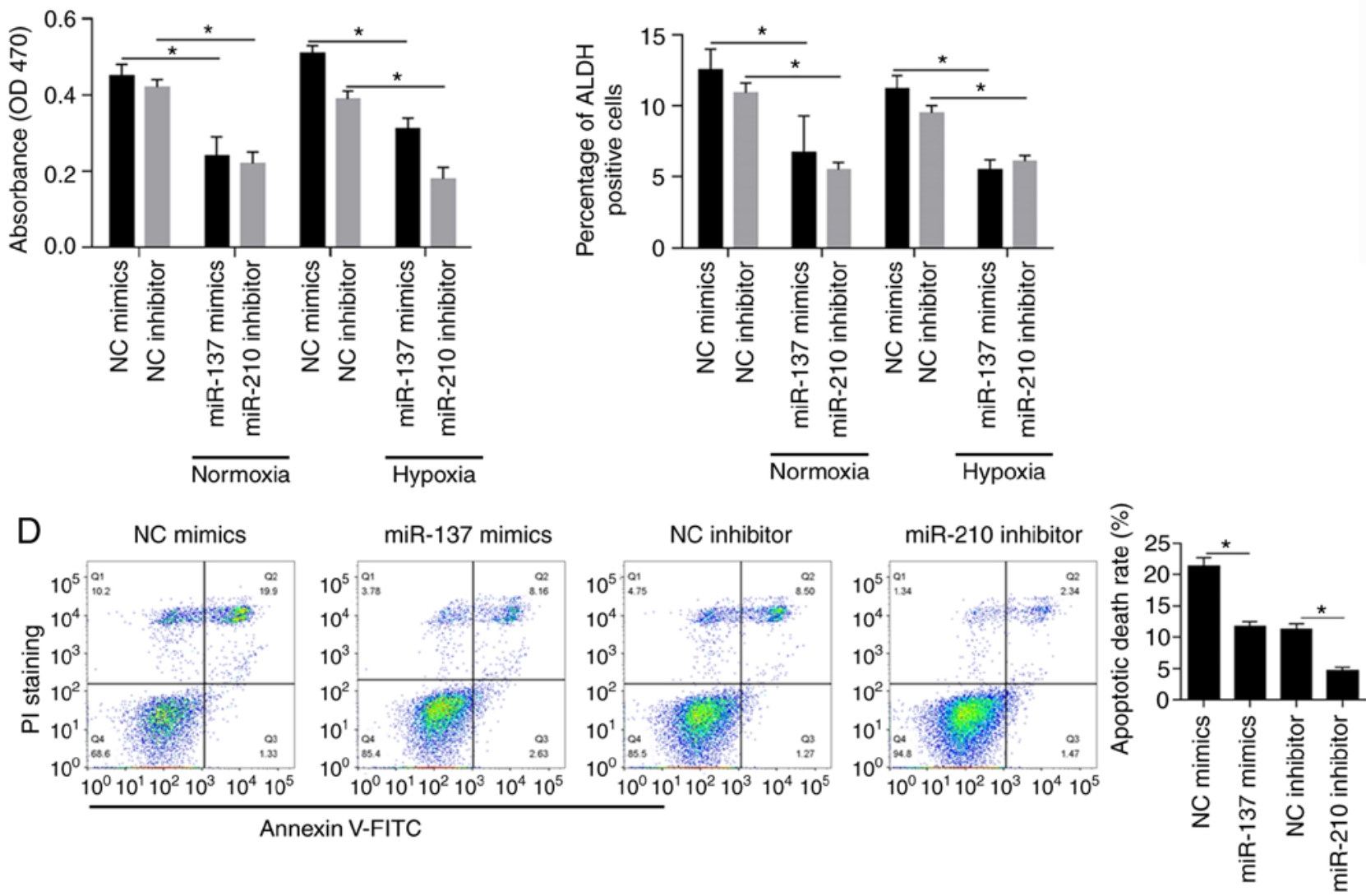

Figure 2. Effects of miR-137 and miR-210 on cell cycle distribution, cell viability, cell stemness and apoptosis. (A) The effects of miR-137 mimics or miR-210 inhibitor on cell cycle phases were measured by performing flow cytometry after PI staining (left panel). Cell cycle phases by statistical analysis (right panel). ${ }^{*} \mathrm{P}<0.05$ vs. NC mimics group; ${ }^{*} \mathrm{P}<0.05$, vs. NC inhibitor group. (B) Cell viability analysis was carried out by performing CCK- 8 assay after transfection of miR-137 mimics or miR-210 inhibitor into BCSCs. "P<0.05 vs. NC mimics group or NC inhibitor group. (C) ALDH-positive subpopulation of BCSCs after transfection of miR-137 mimics or miR-210 inhibitor was measured by flow cytometric analysis. " $\mathrm{P}<0.05$ vs. NC mimics group or NC inhibitor group. (D) Apoptotic cell death was assessed out by performing Annexin V/PI double staining after transfection of miR-137 mimics or miR-210 inhibitor (left panel). Apoptotic cell death by statistical analysis (right panel). "P<0.05 vs. NC mimics group or NC inhibitor group. BCSCs, breast cancer stem-like cells; ALDH, aldehyde dehydrogenase; NC, negative control.

stem-like cells (BCSCs) were formed successfully when the cells were cultured with three cell cytokines, and hypoxia reduced cell viability, as anticipated. Additionally, low oxygen induced the downregulation of miR-137 in breast cancer stem-like cell lines. To verify the phenomenon described above, we further detected the expression of miR-137 in BCSCs under hypoxic conditions. Overexpression of miR-137 promoted
BCSC survival but inhibited cell proliferation, viability and stemness. To investigate the relationship between miR-137 and BCSC mitochondria in hypoxia, we implemented a series of mitochondria-relevant experiments. These data indicated that overexpression of miR-137 led to a significant reduction in ROS in abnormal mitochondria induced by hypoxia and suppressed mitophagy while decreasing the protein levels of 

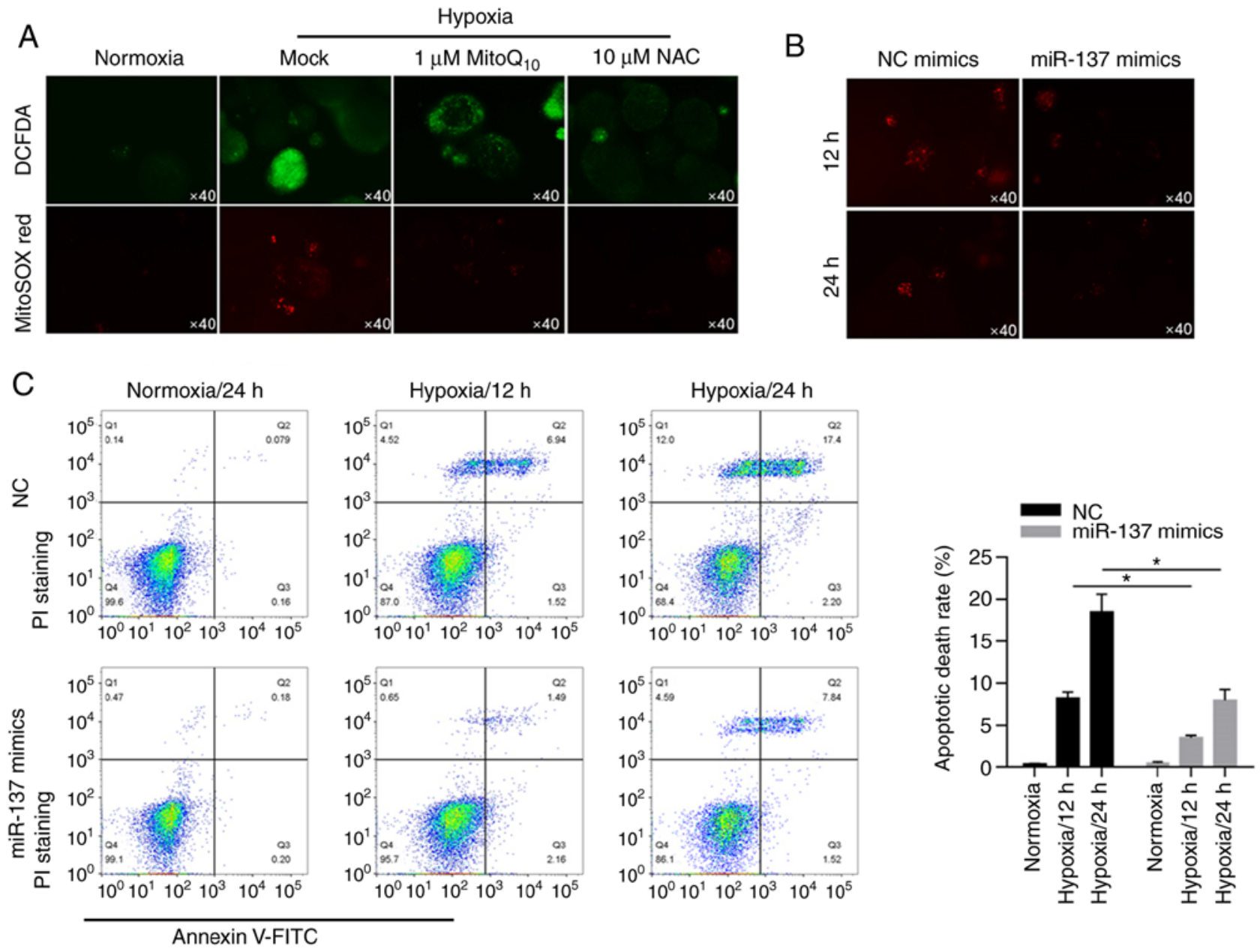

Figure 3. miR-137 suppresses the increase in ROS caused by hypoxia to suppress apoptotic cell death. (A) DCFDA and MitoSOX red staining were performed to detect the production of total ROS and mitochondrial ROS in MCF-7 BCSCs in normoxia or in hypoxia following $1 \mu \mathrm{M}$ MitoQ10 or $10 \mu \mathrm{M}$ NAC treatment. (B) Expression of mitochondrial ROS in miR-137 mimics-treated BCSCs at 12 and 24 h time points. (C) Apoptotic cell death of miR-137-overexpressing BCSCs in normoxic or hypoxic condition by Annexin V/PI double staining at $0,12,24 \mathrm{~h}$ time points (left panel). Apoptotic cell death by statistical analysis (right panel). ${ }^{*} \mathrm{P}<0.05$ vs. NC group. BCSCs, breast cancer stem-like cells; ROS, reactive oxygen species.

FUN14 domain containing 1 (Fundc1) and NIX. The function of intracellular mitochondria was demonstrated to improve under treatment with miR-137.

ROS accumulation induced by hypoxia is frequently a major cause of cell injury and thus promotes apoptotic cell death in cancer cells (53). One of the main reasons for its fatal effects is that ROS disrupt mitochondrial homeostasis by decreasing mitochondrial membrane potential, thus leading to mitochondrial dysfunction, including a decrease in ATP synthesis and transcriptional activity (54). Notably, according to our results, the introduction of miR-137 mimics decreased mitochondrial ROS under hypoxia exposure and simultaneously significantly inhibited the proliferation of BCSCs, which is considered to be controversial. These conflicting results may be due to miR-137 scavenging ROS and inhibition of proliferation in two independent mechanisms. Another possibility is that miR-137 may sensitize cells to accumulated ROS, resulting in low cell viability and low ROS levels.

miR-137, found mainly in the brain $(55,56)$, is involved in many regulatory mechanisms of different types of cancer. In ulcerative colitis-associated colorectal cancer patients, methylation of miR-137 showed a rising trend related to age (57).
Cui et al also reported lower expression of miR-137 in hepatocellular carcinoma in pathological tissue compared with peripheral tissue (58). Another study showed that miR-137 inhibited the growth of oligodendroglial tumor cells by targeting CSE1L (59). miR-137 was found to play a negative role in the therapeutic resistance to drugs in breast cancer cell lines, including fulvestrant (60) and FSTL1 targeting chemoresistance (61). In addition, miR-137 was also found to play an important role in the EMT of breast cancer cells concurrent with the reduction in bone morphogenetic protein-7 (BMP7) (62), the upregulation of E-cadherin and the downregulation of $\mathrm{N}$-cadherin and vimentin (63). Notably, many studies have identified miR-137 regulation of cancer stem-like cell stemness in recent years. For example, He et al (64) found that targeting of KLF12 by miR-137 inhibited the CSC phenotype of pancreatic cancer cells by blocking Wnt/ $\beta$-catenin signaling activity. In addition, miR-137 suppressed the Wnt/ $\beta$-catenin signaling pathway, breast cancer cell stemness, and multi-drug chemoresistance by negatively regulating FSTL1 expression (61).

However, their physiological roles have, until now, not been elucidated in BCSCs. Thus, we used $\mathrm{CoCl}_{2}$ to create a 


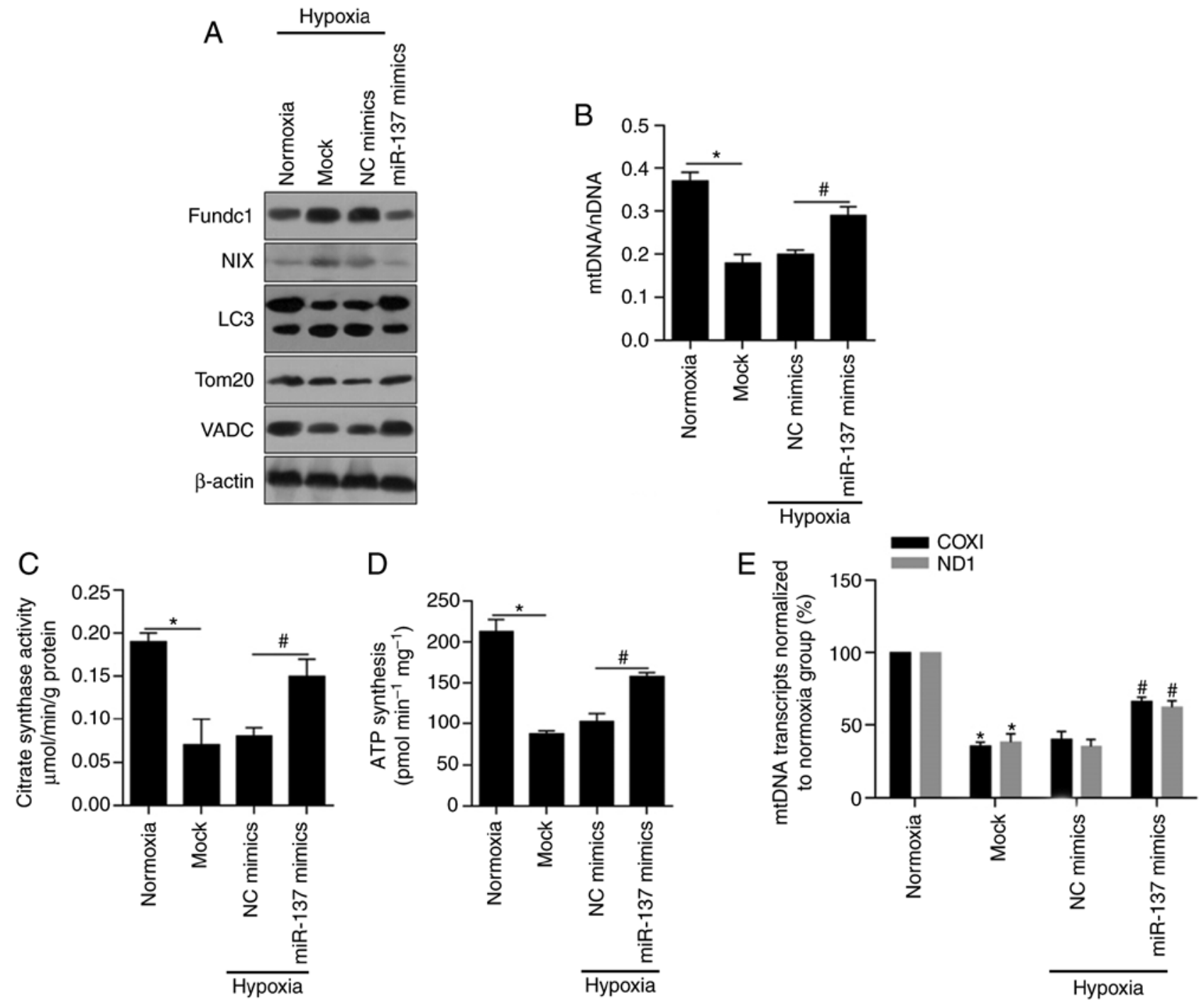

Figure 4. miR-137 restores the cell mitochondrial dysfunction by inhibiting mitophagy. (A) Western blotting was performed to detect the protein levels of Fundc1, NIX, LC3, Tom 20 and VADC in BCSCs after introduction of miR-137 mimics. (B) The mtDNA levels in BCSCs after introduction of miR-137 mimics were assessed by RT-qPCR. " $\mathrm{P}<0.05$, vs. Normoxia group; ${ }^{~} \mathrm{P}<0.05$, vs. NC mimics group. (C) Citrate synthase activity was measured by Citrate Synthase Activity Colorimetric Assay Kit. ${ }^{*} \mathrm{P}<0.05$, vs. Normoxia group; ${ }^{\prime} \mathrm{P}<0.05$, vs. NC mimics group. (D) Synthesized ATP was analyzed by ATP synthase Assay Kit. "P<0.05, vs. Normoxia group; ${ }^{*} \mathrm{P}<0.05$, vs. NC mimics group. (E) The mtDNA transcription activity was measured by assessing the expression of COXI and ND1. "P $<0.05$, vs. Normoxia group; ${ }^{*} \mathrm{P}<0.05$, vs. NC mimics group. BCSCs, breast cancer stem-like cells; mtDNA, mitochondrial DNA; NIX, also known as beclin-2 (BCL2); Fundc1, Fun14 domain-containing protein 1; VADC, voltage-dependent anion channel; LC3, light chain 3; Tom20, mitochondrial import receptor subunit TOM20 homolog; COXI, cytochrome $c$ oxidase I; ND1, NADH-ubiquinone oxidoreductase chain 1; NC, negative control.

low-oxygen environment, which showed that hypoxia could enhance BCSC mitophagy. Notably, after overexpression of miR-137, BCSCs exhibited the opposite tendencies in cell growth and cell apoptosis. These findings showed that upregulation of miR-137 not only improved BCSC survival but also inhibited BCSC stemness. Subsequently, we explored the intracellular changes in mitochondria in BCSCs cocultured with miR-137 mimics. Our data revealed that the overexpression of miR-137 inhibited cell apoptosis by reducing hypoxia-induced abnormal mitochondrial homeostasis. Moreover, after carrying out further protein experiments, we found an inhibitory role of miR-137 in mitophagy in BCSCs. In the present study, we established for the first time a new regulatory pathway for miR-137, malignant behavior, and mitochondrial activity in BCSCs. Interestingly, our findings that the miR-137-mediated downregulation of mitophagy inhibited hypoxia-induced
BCSC apoptosis and maintained mitochondrial function are related to the study by Chen et al showing that overexpression of miR-137 inhibited stemness of triple negative breast cancer (TNBC) cells and tumor formation by downregulating B-cell lymphoma/leukaemia 11A (65). However, Chen et al indicated that the miR-137-mediated disruption of the B-cell lymphoma/leukaemia 11A-DNA methyltransferase 1 interaction impaired BCSC stemness and tumorigenesis by suppressing ISL-1. Similarly, we confirmed the negative regulation of mitochondrial metabolism by miR-137, which resulted in failure to provide enough energy to maintain BCSC stemness under nonphysiological hypoxia conditions, which demonstrated another regulatory effect of miR-137 on BCSC stemness and tumor development. The results of the present study further confirmed the protective effect of miR-137 in hypoxia-induced BCSC mitochondrial dysfunction, which 

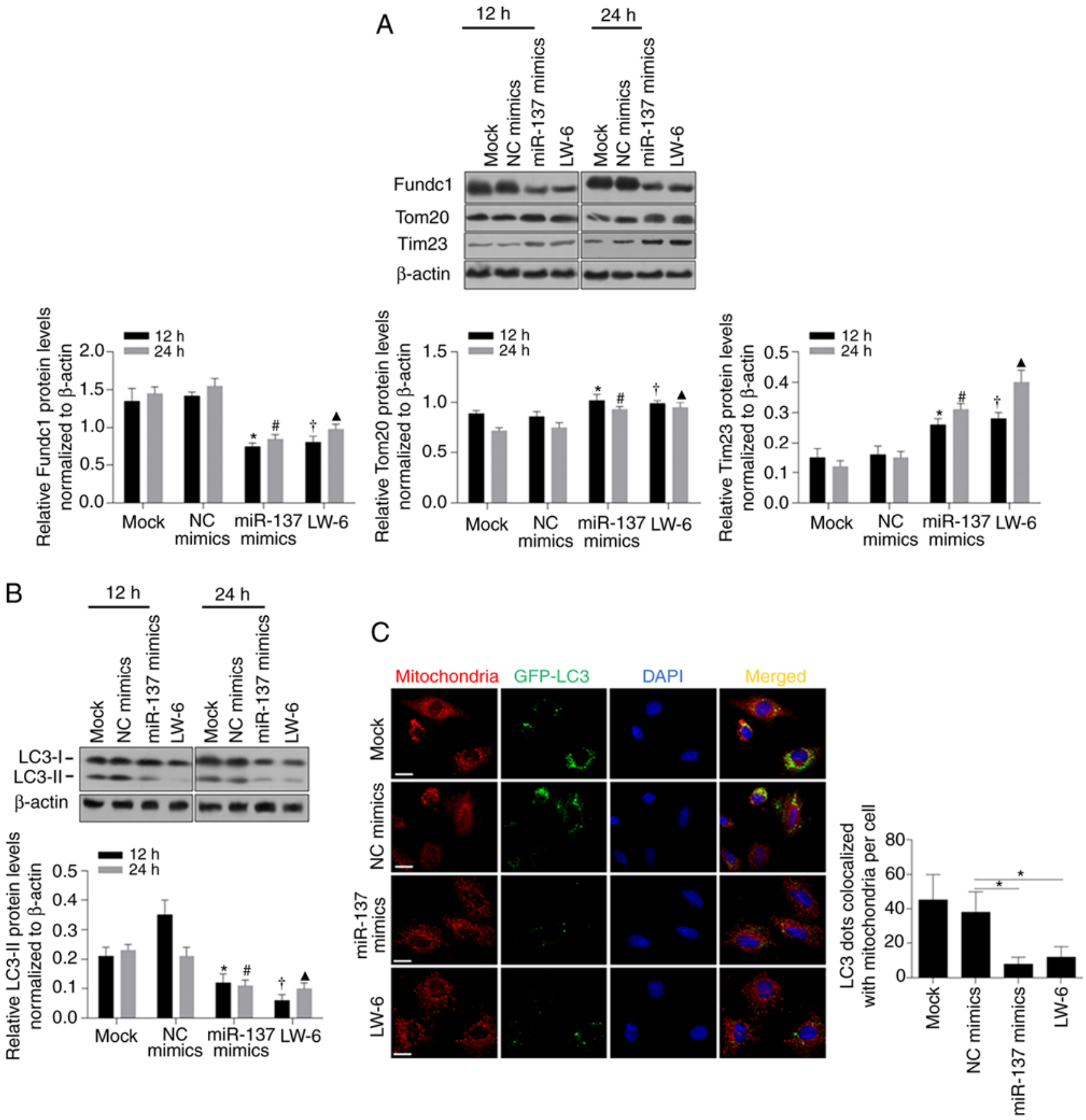

Figure 5. miR-137 regulates mitophagy via targeting Fundc1. (A) Western blotting was performed to detect Fundc1, Tom20, and Tim23 after introduction of miR-137 mimics or treatment with LW-6 after 12 or $24 \mathrm{~h}$ (upper panel). Fundc1, Tom20, and Tim23 protein expression by statistical analysis (lower panels). ${ }^{\prime} \mathrm{P}<0.05$, vs. $12 \mathrm{~h} \mathrm{NC}$ mimics group; ${ }^{\prime} \mathrm{P}<0.05$, vs. $24 \mathrm{~h} \mathrm{NC}$ mimics group; ${ }^{\dagger} \mathrm{P}<0.05$, vs. $12 \mathrm{~h}$ Mock group; ${ }^{\circ} \mathrm{P}<0.05$, vs. $24 \mathrm{~h}$ Mock group. (B) The protein expression level of LC3 (upper panel). LC3-II protein expression by statistical analysis (lower panel). ${ }^{*} \mathrm{P}<0.05$, vs. $12 \mathrm{~h} \mathrm{NC}$ mimics group; ${ }^{*} \mathrm{P}<0.05$, vs. $24 \mathrm{~h} \mathrm{NC}$ mimics group; ${ }^{\dagger} \mathrm{P}<0.05$, vs. $12 \mathrm{~h}$ Mock group; ${ }^{\mathrm{A}} \mathrm{P}<0.05$, vs. $24 \mathrm{~h}$ Mock group. (C) The colocalization of LC3 with mitochondria (left panel). LC 3 dots colocalized with mitochondria per cell by statistical analysis (right panel). ${ }^{*} \mathrm{P}<0.05$, vs. $\mathrm{NC}$ mimics group. Fundc1, Fun14 domain-containing protein 1 ; LC3, light chain 3 ; Tom20, mitochondrial import receptor subunit TOM20 homolog; Tim23, mitochondrial import inner membrane translocase subunit Tim23; NC, negative control.

establishes a connection between microRNA and mitophagy receptors bound to LC3 involved in mitophagy.

Although important findings have been revealed by the present study, there are also limitations. It should be noted that this study examined only protein alterations of Fundc1. The results are incomplete and cannot be taken as evidence that Fundc1 is a direct target of miR-137. Bioinformatics analysis and dual luciferase reporter assays should be performed to evaluate the direct binding of miR-137 with its targets. Moreover, no study was conducted using nude mice, and whether miR-137 is effective in the prevention of breast cancer stemness and tumor formation still requires further research and verification. In addition, miR-210 has been reported to negatively regulate E-cadherin in hypoxic BCSCs to promote cell metastasis, proliferation, and self-renewal (66). In the present study, we also discovered the activation of miR-210, which indicated the possibility of targeting miR-210 in hypoxia-induced cell injury. This 
finding prompted us to determine whether an inhibitor of miR-210 exerts its therapeutic effects by regulating the expression of mitophagy-related proteins consistent with the introduction of miR-137. Overall, we can clearly outline our next steps. In summary, considering all the molecular analyses of BCSCs mentioned above, we tentatively propose that miR-137 may be a potential therapeutic target for breast cancer. Moreover, further investigations are needed to clarify whether miR-137 is an effective and safe therapy for breast cancer in humans and elucidate its comprehensive molecular regulatory mechanism on BCSC mitophagy.

\section{Acknowledgements}

Not applicable.

\section{Funding}

This study was supported by the National Natural Science Foundation of China (nos. 81601835 and 81973684), the Department of Science and Technology of Sichuan Province (no. 18YYJC0689) and the Health and Family Planning Commission of Sichuan Province (no. 18ZD039).

\section{Availability of data and materials}

The datasets used during the present study are available from the corresponding author upon reasonable request.

\section{Authors' contributions}

$\mathrm{ZZ}$ and $\mathrm{CX}$ contributed to the study design. QH and $\mathrm{YY}$ contributed to data collection and figure construction. YW and $\mathrm{YH}$ contributed to the literature search. All authors read and approved the manuscript and agree to be accountable for all aspects of the research in ensuring that the accuracy or integrity of any part of the work are appropriately investigated and resolved.

\section{Ethics approval and consent to participate}

Not applicable.

\section{Patient consent for publication}

Not applicable.

\section{Competing interests}

The authors state that they have no competing interests.

\section{References}

1. Bray F, Ferlay J, Soerjomataram I, Siegel RL, Torre LA and Jemal A: Global cancer statistics 2018: GLOBOCAN estimates of incidence and mortality worldwide for 36 cancers in 185 countries. CA Cancer J Clin 68: 394-424, 2018.

2. Momenimovahed $\mathrm{Z}$ and Salehiniya H: Epidemiological characteristics of and risk factors for breast cancer in the world. Breast Cancer (Dove Med Press) 11: 151-164, 2019.

3. Sousa B, Ribeiro AS and Paredes J: Heterogeneity and plasticity of breast cancer stem cells. Adv Exp Med Biol 1139: 83-103, 2019.
4. Kong Y, Lyu N, Wu J, Tang H, Xie X, Yang L, Li X, Wei W and Xie X: Breast cancer stem cell markers CD44 and ALDH1A1 in serum: Distribution and prognostic value in patients with primary breast cancer. J Cancer 9: 3728-3735, 2018.

5. Sjöström M, Hartman L, Honeth G, Grabau D, Malmström $P$, Hegardt C, Fernö M and Niméus E: Stem cell biomarker ALDH1A1 in breast cancer shows an association with prognosis and clinicopathological variables that is highly cut-off dependent. J Clin Pathol 68: 1012-1019, 2015.

6. Yang F, Cao L, Sun Z, Jin J, Fang H, Zhang W and Guan X: Evaluation of breast cancer stem cells and intratumor stemness heterogeneity in triple-negative breast cancer as prognostic factors. Int J Biol Sci 12: 1568-1577, 2016.

7. Seo AN, Lee HJ, Kim EJ, Jang MH, Kim YJ, Kim JH, Kim SW, Ryu HS, Park IA, Im SA, et al: Expression of breast cancer stem cell markers as predictors of prognosis and response to trastuzumab in HER2-positive breast cancer. Br J Cancer 114: 1109-1116, 2016.

8. Sulaiman A, McGarry S, Li L, Jia D, Ooi S, Addison C, Dimitroulakos J, Arnaout A, Nessim C, Yao Z, et al: Dual inhibition of Wnt and Yes-associated protein signaling retards the growth of triple-negative breast cancer in both mesenchymal and epithelial states. Mol Oncol 12: 423-440, 2018.

9. Yuan X, Wu H, Xu H, Xiong H, Chu Q, Yu S, Wu GS and Wu K: Notch signaling: An emerging therapeutic target for cancer treatment. Cancer Lett 369: 20-27, 2015.

10. O'Toole SA, Machalek DA, Shearer RF, Millar EK, Nair R, Schofield P, McLeod D, Cooper CL, McNeil CM, McFarland A, et al: Hedgehog overexpression is associated with stromal interactions and predicts for poor outcome in breast cancer. Cancer Res 71: 4002-4014, 2011.

11. Palomeras S, Ruiz-Martínez S and Puig T: Targeting breast cancer stem cells to overcome treatment resistance. Molecules 23: 2193 , 2018.

12. Nwabo Kamdje AH, Seke Etet PF, Vecchio L, Muller JM, Krampera $M$ and Lukong KE: Signaling pathways in breast cancer: Therapeutic targeting of the microenvironment. Cell Signal 26: 2843-2856, 2014.

13. Maruthanila VL, Elancheran R, Kunnumakkara AB, Kabilan S and Kotoky J: Recent development of targeted approaches for the treatment of breast cancer. Breast Cancer 24: 191-219, 2017.

14. Nobre AR, Entenberg D, Wang Y, Condeelis J and Aguirre-Ghiso JA: The different routes to metastasis via hypoxia-regulated programs. Trends Cell Biol 28: 941-956, 2018.

15. Abe H, Semba $\mathrm{H}$ and Takeda $\mathrm{N}$ : The roles of hypoxia signaling in the pathogenesis of cardiovascular diseases. J Atheroscler Thromb 24: 884-894, 2017.

16. Fuhrmann DC and Brüne B: Mitochondrial composition and function under the control of hypoxia. Redox Biol 12: 208-215, 2017.

17. Tong WW, Tong GH and Liu Y: Cancer stem cells and hypoxia-inducible factors (Review). Int J Oncol 53: 469-476, 2018.

18. Keith B and Simon MC: Hypoxia-inducible factors, stem cells, and cancer. Cell 129: 465-472, 2007.

19. Gonzalez FJ, Xie C and Jiang C: The role of hypoxia-inducible factors in metabolic diseases. Nat Rev Endocrinol 15: 21-32, 2018

20. Mazumdar J, O'Brien WT, Johnson RS, LaManna JC, Chavez JC, Klein PS and Simon MC: $\mathrm{O}_{2}$ regulates stem cells through Wnt/ß -catenin signalling. Nat Cell Biol 12: 1007-1013, 2010.

21. Zhang Z, Han H, Rong Y, Zhu K, Zhu Z, Tang Z, Xiong C and Tao J: Hypoxia potentiates gemcitabine-induced stemness in pancreatic cancer cells through AKT/Notch1 signaling. J Exp Clin Cancer Res 37: 291, 2018.

22. Catalano V, Turdo A, Di Franco S, Dieli F, Todaro M and Stassi G: Tumor and its microenvironment: A synergistic interplay. Semin Cancer Biol 23: 522-532, 2013.

23. Mohr AM and Mott JL: Overview of microRNA biology. Semin Liver Dis 35: 3-11, 2015.

24. Bandara KV, Michael MZ and Gleadle JM: MicroRNA biogenesis in hypoxia. Microrna 6: 80-96, 2017.

25. Li W, Zhang X, Zhuang H, Chen HG, Chen Y, Tian W, Wu W, Li Y, Wang S, Zhang L, et al: MicroRNA-137 is a novel hypoxia-responsive microRNA that inhibits mitophagy via regulation of two mitophagy receptors FUNDC1 and NIX. J Biol Chem 289: 10691-10701, 2014.

26. Li H, Zhu Z, Liu J, Wang J and Qu C: MicroRNA-137 regulates hypoxia-induced retinal ganglion cell apoptosis through Notch1. Int J Mol Med 41: 1774-1782, 2018.

27. Chang J, Yan X and Zeng Y: Propofol weakens hypoxia-aroused apoptosis and autophagy via elevating microRNA-137 in neurocytes. Exp Mol Pathol 112: 104327, 2020. 
28. Wang H, Flach H, Onizawa M, Wei L, McManus MT and Weiss A: Negative regulation of Hifla expression and TH17 differentiation by the hypoxia-regulated microRNA miR-210. Nat Immunol 15: 393-401, 2014.

29. el Azzouzi H, Leptidis S, Dirkx E, Hoeks J, van Bree B, Brand K, McClellan EA, Poels E, Sluimer JC, van den Hoogenhof MM, et al: The hypoxia-inducible microRNA cluster miR-199a-214 targets myocardial PPAR $\delta$ and impairs mitochondrial fatty acid oxidation. Cell Metab 18: 341-354, 2013

30. Chan SY, Zhang YY, Hemann C, Mahoney CE, Zweier JL and Loscalzo J: MicroRNA-210 controls mitochondrial metabolism during hypoxia by repressing the iron-sulfur cluster assembly proteins ISCU1/2. Cell Metab 10: 273-284, 2009.

31. Zhang X, Ji R, Liao X, Castillero E, Kennel PJ, Brunjes DL, Franz M, Möbius-Winkler S, Drosatos K, George I, et al: MicroRNA-195 regulates metabolism in failing myocardium via alterations in sirtuin 3 expression and mitochondrial protein acetylation. Circulation 137: 2052-2067, 2018.

32. Li H, Zhang X, Wang F, Zhou L, Yin Z, Fan J, Nie X, Wang P, Fu XD, Chen C and Wang DW: MicroRNA-21 lowers blood pressure in spontaneous hypertensive rats by upregulating mitochondrial translation. Circulation 134: 734-751, 2016.

33. Ullmann P, Nurmik M, Begaj R, Haan S and Letellier E: Hypoxia- and microRNA-induced metabolic reprogramming of tumor-initiating cells. Cells 8: 528, 2019.

34. Jafari $\mathrm{N}$ and Abediankenari S: MicroRNA-34 dysregulation in gastric cancer and gastric cancer stem cell. Tumour Biol 39: $1010428317701652,2017$.

35. Grosso S, Doyen J, Parks SK, Bertero T, Paye A, Cardinaud B, Gounon P, Lacas-Gervais S, Noël A, Pouysségur J, et al: miR-210 promotes a hypoxic phenotype and increases radioresistance in human lung cancer cell lines. Cell Death Dis 4: e544, 2013.

36. Gee HE, Ivan C, Calin GA and Ivan M: HypoxamiRs and cancer: From biology to targeted therapy. Antioxid Redox Signal 21: 1220-1238, 2014

37. Qin Q, Furong W and Baosheng L: Multiple functions of hypoxiaregulated miR-210 in cancer. J Exp Clin Cancer Res 33: 50, 2014.

38. Livak KJ and Schmittgen TD: Analysis of relative gene expression data using real-time quantitative PCR and the 2(-Delta Delta C(T)) method. Methods 25: 402-408, 2001

39. Almozyan S, Colak D, Mansour F, Alaiya A, Al-Harazi O, Qattan A, Al-Mohanna F, Al-Alwan M and Ghebeh H: PD-L1 promotes OCT4 and Nanog expression in breast cancer stem cells by sustaining PI3K/AKT pathway activation. Int J Cancer 141: $1402-1412,2017$

40. Yin X, Zhang BH, Zheng SS, Gao DM, Qiu SJ, Wu WZ and Ren ZG: Coexpression of gene Oct4 and Nanog initiates stem cell characteristics in hepatocellular carcinoma and promotes epithelial-mesenchymal transition through activation of Stat3/Snail signaling. J Hematol Oncol 8: 23, 2015

41. Wang D, Lu P, Zhang H, Luo M, Zhang X, Wei X, Gao J, Zhao Z and Liu C: Oct-4 and Nanog promote the epithelial-mesenchymal transition of breast cancer stem cells and are associated with poor prognosis in breast cancer patients. Oncotarget 5: 10803-10815, 2014.

42. Jeter CR, Yang T, Wang J, Chao HP and Tang DG: Concise review: NANOG in cancer stem cells and tumor development: An update and outstanding questions. Stem Cells 33: 2381-2390, 2015.

43. Charafe-Jauffret E, Ginestier C, Iovino F, Tarpin C, Diebel M, Esterni B, Houvenaeghel G, Extra JM, Bertucci F, Jacquemier $\mathrm{J}$, et al: Aldehyde dehydrogenase 1-positive cancer stem cells mediate metastasis and poor clinical outcome in inflammatory breast cancer. Clin Cancer Res 16: 45-55, 2010.

44. Ginestier C, Hur MH, Charafe-Jauffret E, Monville F, Dutcher J, Brown M, Jacquemier J, Viens P, Kleer CG, Liu S, et al: ALDH1 is a marker of normal and malignant human mammary stem cells and a predictor of poor clinical outcome. Cell Stem Cell 1: 555-567, 2007.

45. Balicki D: Moving forward in human mammary stem cell biology and breast cancer prognostication using ALDH1. Cell Stem Cell 1: 485-487, 2007.

46. $\mathrm{Wu} \mathrm{H}$ and Chen Q: Hypoxia activation of mitophagy and its role in disease pathogenesis. Antioxid Redox Signal 22: 1032-1046, 2015.

47. Zhang H, Gao P, Fukuda R, Kumar G, Krishnamachary B, Zeller KI, Dang CV and Semenza GL: HIF-1 inhibits mitochondrial biogenesis and cellular respiration in VHL-deficient renal cell carcinoma by repression of C-MYC activity. Cancer Cell 11: 407-420, 2007
48. Liu L, Sakakibara K, Chen Q and Okamoto K: Receptor-mediated mitophagy in yeast and mammalian systems. Cell Res $24:$ 787-795, 2014.

49. Wu X, Wu FH, Wu Q, Zhang S, Chen S and Sima M: Phylogenetic and molecular evolutionary analysis of mitophagy receptors under hypoxic conditions. Front Physiol 8: 539, 2017.

50. van der Laan M, Rissler M and Rehling P: Mitochondrial preprotein translocases as dynamic molecular machines. FEMS Yeast Res 6: 849-861, 2006

51. DeHart DN, Fang D, Heslop K, Li L, Lemasters JJ and Maldonado EN: Opening of voltage dependent anion channels promotes reactive oxygen species generation, mitochondrial dysfunction and cell death in cancer cells. Biochem Pharmacol 148: 155-162, 2018.

52. Chen Z, Siraj S, Liu L and Chen Q: MARCH5-FUNDC1 axis fine-tunes hypoxia-induced mitophagy. Autophagy 13 1244-1245, 2017

53. Hielscher A and Gerecht S: Hypoxia and free radicals: Role in tumor progression and the use of engineering-based platforms to address these relationships. Free Radic Biol Med 79: 281-291, 2015.

54. Shadel GS and Horvath TL: Mitochondrial ROS signaling in organismal homeostasis. Cell 163: 560-569, 2015.

55. Arakawa Y, Yokoyama K, Tasaki S, Kato J, Nakashima K, Takeyama M, Nakatani A and Suzuki M: Transgenic mice overexpressing miR-137 in the brain show schizophrenia-associated behavioral deficits and transcriptome profiles. PLoS One 14: e0220389, 2019.

56. Guella I, Sequeira A, Rollins B, Morgan L, Torri F, van Erp TG, Myers RM, Barchas JD, Schatzberg AF, Watson SJ, et al: Analysis of miR-137 expression and rs1625579 in dorsolateral prefrontal cortex. J Psychiatr Res 47: 1215-1221, 2013.

57. Toiyama Y, Okugawa Y, Tanaka K, Araki T, Uchida K, Hishida A, Uchino M, Ikeuchi H, Hirota S, Kusunoki M, et al: A panel of methylated MicroRNA biomarkers for identifying high-risk patients with ulcerative colitis-associated colorectal cancer. Gastroenterology 153: 1634-1646.e8, 2017.

58. Cui S, Sun Y, Liu Y, Liu C, Wang J, Hao G and Sun Q: MicroRNA-137 has a suppressive role in liver cancer via targeting EZH2. Mol Med Rep 16: 9494-9502, 2017.

59. Li KK, Yang L, Pang JC, Chan AK, Zhou L, Mao Y, Wang Y, Lau KM, Poon WS, Shi Z and Ng HK: MIR-137 suppresses growth and invasion, is downregulated in oligodendroglial tumors and targets CSE1L. Brain Pathol 23: 426-439, 2013

60. Guo J, He K, Zeng H, Shi Y, Ye P, Zhou Q, Pan Z and Long X: Differential microRNA expression profiles determined by next-generation sequencing in three fulvestrant-resistant human breast cancer cell lines. Oncol Lett 17: 3765-3776, 2019.

61. Cheng S, Huang Y, Lou C, He Y, Zhang Y and Zhang Q: FSTL1 enhances chemoresistance and maintains stemness in breast cancer cells via integrin $\beta 3 /$ Wnt signaling under miR-137 regulation. Cancer Biol Ther 20: 328-337, 2019.

62. Ying X, Sun Y and He P: MicroRNA-137 inhibits BMP7 to enhance the epithelial-mesenchymal transition of breast cancer cells. Oncotarget 8: 18348-18358, 2017.

63. Han Y, Bi Y, Bi H, Diao C, Zhang G, Cheng K and Yang Z: miR-137 suppresses the invasion and procedure of EMT of human breast cancer cell line MCF-7 through targeting CtBP1. Hum Cell 29: 30-36, 2016.

64. He Z, Guo X, Tian S, Zhu C, Chen S, Yu C, Jiang J and Sun C: MicroRNA-137 reduces stemness features of pancreatic cancer cells by targeting KLF12. J Exp Clin Cancer Res 38: 126, 2019.

65. Chen F, Luo N, Hu Y, Li X and Zhang K: miR-137 suppresses triple-negative breast cancer stemness and tumorigenesis by perturbing BCL11A-DNMT1 interaction. Cell Physiol Biochem 47: 2147-2158, 2018

66. Tang T, Yang Z, Zhu Q, Wu Y, Sun K, Alahdal M, Zhang Y, Xing Y, Shen Y, Xia T, et al: Up-regulation of miR-210 induced by a hypoxic microenvironment promotes breast cancer stem cells metastasis, proliferation, and self-renewal by targeting E-cadherin. FASEB J: Sep 6, 2018 (Epub ahead of print).

This work is licensed under a Creative Commons Attribution-NonCommercial-NoDerivatives 4.0 International (CC BY-NC-ND 4.0) License. 